\title{
Somatic and psychologic predictors of long-term unfavorable outcome after surgical intervention
}

Citation for published version (APA):

Peters, M. L., Sommer, M., de Rijke, J. M., Kessels, A. G. H., Heineman, E., Patijn, J., Marcus, M. A., Vlaeyen, J. W., \& van Kleef, M. (2007). Somatic and psychologic predictors of long-term unfavorable outcome after surgical intervention. Annals of Surgery, 245(3), 487-494.

https://doi.org/10.1097/01.sla.0000245495.79781.65

Document status and date:

Published: 01/01/2007

DOI:

10.1097/01.sla.0000245495.79781.65

Document Version:

Publisher's PDF, also known as Version of record

Document license:

Taverne

Please check the document version of this publication:

- A submitted manuscript is the version of the article upon submission and before peer-review. There can be important differences between the submitted version and the official published version of record.

People interested in the research are advised to contact the author for the final version of the publication, or visit the DOI to the publisher's website.

- The final author version and the galley proof are versions of the publication after peer review.

- The final published version features the final layout of the paper including the volume, issue and page numbers.

Link to publication

\footnotetext{
General rights rights.

- You may freely distribute the URL identifying the publication in the public portal. please follow below link for the End User Agreement:

www.umlib.nl/taverne-license

Take down policy

If you believe that this document breaches copyright please contact us at:

repository@maastrichtuniversity.nl

providing details and we will investigate your claim.
}

Copyright and moral rights for the publications made accessible in the public portal are retained by the authors and/or other copyright owners and it is a condition of accessing publications that users recognise and abide by the legal requirements associated with these

- Users may download and print one copy of any publication from the public portal for the purpose of private study or research.

- You may not further distribute the material or use it for any profit-making activity or commercial gain

If the publication is distributed under the terms of Article $25 \mathrm{fa}$ of the Dutch Copyright Act, indicated by the "Taverne" license above, 


\title{
Somatic and Psychologic Predictors of Long-term Unfavorable Outcome After Surgical Intervention
}

\author{
Madelon L. Peters, PhD, * Micha Sommer, MD, † Janneke M. de Rijke, PhD, $\uparrow$ \\ Fons Kessels, MD, MSc, $\neq$ Erik Heineman, MD, PhD, $\S$ Jacob Patijn, MD, PhD, $\dagger$ \\ Marco A. E. Marcus, MD, PhD, † Johan W. S. Vlaeyen, PhD, * and Maarten van Kleef, MD, PhD $\dagger$
}

\begin{abstract}
Objective: To identify somatic and psychologic predictors of pain, functional limitations, global perceived recovery, and quality of life 6 months after surgical intervention.

Summary Background Data: Recent studies have indicated that chronic pain after surgical intervention is more common than previously assumed. Several demographic and somatic predictors of long-term unfavorable outcome have been identified, but little is known about the contribution of psychologic risk factors.
\end{abstract}

Methods: A prospective cohort study, including 625 patients undergoing elective surgery at the University Hospital Maastricht, The Netherlands, was conducted between February and August 2003. Psychologic questionnaires were completed preoperatively and acute postoperative pain was recorded until 4 days after the operation. Six months later, all patients received follow-up questionnaires to assess pain, functional limitations, global perceived recovery, and quality of life. Multivariable logistic regression analyses were used to estimate relative risk of poor outcome in terms of pain, functional limitations, and global recovery. Multivariable linear regression analysis was used to assess associations with quality of life at 6 months.

Results: The most important somatic predictors of unfavorable outcome were duration of the operation and high levels of acute postoperative pain. Patients reporting high levels of pain 4 days after the operation and patients undergoing an operation of longer than 3 hours were at risk for increased pain, increased functional limitations, poor global recovery, and reported lower levels of quality of life 6 months after the operation. Psychologic variables that influenced long-term outcome were preoperative fear of surgery and optimism. Fear of the long-term consequences of the operation was associated with more pain, poor global recovery, and worse quality of life 6 months later, whereas optimism was associated with better recovery and higher quality of life.

From the *Department of Medical, Clinical and Experimental Psychology, Maastricht University, Maastricht, The Netherlands; and the Departments of †Anesthesiology and Pain Treatment, †Epidemiology, and §Surgery, University Hospital Maastricht, Maastricht, The Netherlands.

Supported by a grant (Grant No. 110000007) from the Dutch Foundation of Scientific Research (Zon-MW).

Reprints: Madelon L. Peters, PhD, Department of Medical, Clinical and Experimental Psychology, Maastricht University, P.O. Box 616, 6200 MD Maastricht, The Netherlands. E-mail: Madelon.Peters@dep.unimaas.nl.

Copyright (C) 2007 by Lippincott Williams \& Wilkins

ISSN: 0003-4932/07/24503-0487

DOI: $10.1097 / 01$. sla.0000245495.79781.65
Conclusions: This study was the first to identify the joint contribution of somatic and psychologic factors to chronic pain, functional limitations, and quality of life 6 months after surgical interventions. It replicates previous findings that intense acute postoperative pain is a risk factor for long-term adverse outcome and also identified additional risk factors, namely, long duration of the operation, ASA status, and preoperative fear of surgery.

(Ann Surg 2007;245: 487-494)

$\mathrm{R}$ ecent studies have indicated that chronic pain after surgical intervention is more common than previously assumed. Prevalence rates of chronic postoperative pain vary across studies and type of procedures, ranging from approximately $10 \%$ for inguinal hernia operations up to $30 \%$ to $50 \%$ for cardiac surgery. ${ }^{1-12}$ A substantial percentage of patients report that this pain interferes with daily activities and leads to physical impairments. ${ }^{1,5,8-10}$

Nerve injury may be one of the causes of chronic postoperative pain, but not all postoperative pain is of neuropathic origin. ${ }^{4,6}$ Another potential cause of sustained pain is neuroplastic change in the central nervous system induced by high-intensity pain in the first days following surgery. ${ }^{13}$ Several studies found severe acute postoperative pain to be a risk factor for chronic pain., ${ }^{2,9,11,14}$ Other identified risk factors for sustained postoperative pain are younger age, ${ }^{4,6,10}$ female gender, ${ }^{15,16}$ and pain before the operation. ${ }^{2,4,10}$ Psychologic factors have also been proposed to influence postoperative pain. Important determinants of acute postoperative pain intensity appear to be preoperative anxiety and catastrophizing (ie, exaggerated negative beliefs) about pain. ${ }^{17-22}$ However, whether anxiety and catastrophizing also increase the risk of developing chronic postoperative pain remains to be determined. In a review of the literature on predictive factors for chronic postoperative pain, Perkins and Kehlet ${ }^{2}$ conclude that the only reproducible psychologic factor contributing to chronicity is neuroticism.

Psychologic variables may also affect functional recovery after surgery. Catastrophizing about pain was negatively associated and optimism and self-efficacy were positively associated with the speed of functional recovery after various types of surgical interventions. ${ }^{23-27}$ Long-term effects of 
psychologic variables on physical disability and well-being have also been reported. ${ }^{16,25,28,29}$

For the present study, preoperative somatic and psychologic variables and acute postoperative pain were tested as predictors of pain, functional limitations, global perceived recovery, and health-related quality of life at 6 months follow-up in patients undergoing various surgical interventions. By combining somatic and psychologic predictors in a single study the relative contribution of a certain variable after controlling for other variables can be established. Moreover, multiple long-term outcome variables are included allowing assessment of the possible differential predictive power of somatic and psychologic factors for different outcomes.

\section{METHODS}

\section{Patients}

The study was approved by the Ethical Committee of the University Hospital Maastricht, The Netherlands. From February to August 2003, 1975 patients scheduled for elective surgery at the University Hospital Maastricht were approached for participation. Inclusion criteria were: age $>18$ years, understanding of Dutch, surgery at the departments of general surgery, plastic surgery, orthopedics, ophthalmology, gynecology, ear-nose-throat, maxillofacial surgery, urology, neurosurgery, or thoracic surgery. Exclusion criteria were: limitations of self-expression, visual dysfunction, emergency surgery, cardiac surgery, or cesarean section. Informed consent for preoperative and acute postoperative assessment was obtained from 1663 patients $(85 \%)$. Patients $(n=173)$ were excluded from further participation for the following reasons: complications during surgery $(n=14)$, the need for extended postoperative ventilatory support at the intensive care unit $(\mathrm{n}=50)$, research too demanding $(\mathrm{n}=32)$, missing data $(\mathrm{n}=33)$, or logistic reasons (eg, no research assistant available; $n=44$ ). Of the 1490 remaining patients, 1003 gave informed consent to participate in the follow-up study. Follow-up questionnaires were completed by 838 patients. A further 213 patients were excluded because of events occurring in the follow-up period that had a potentially detrimental effect on health but were unrelated to surgical intervention (eg, a car accident; $\mathrm{n}=89$ ) or because they had repeated operations $(\mathrm{n}=124)$. This left 625 patients for follow-up analyses. Mean age of patients was 54.8 year and $53 \%$ was female.

\section{Preoperative Assessment}

Eligible patients received a letter describing the purpose and methods of the study and a set of questionnaires 1 to 3 weeks preceding the operation. The following questionnaires were included: 1) pain catastrophizing scale (PCS): 13 items measuring exaggerated negative interpretation of the meaning of pain; ${ }^{30}$ 2) Behavioral Inhibition Scale (BIS): 7 items measuring anxious temperament; ${ }^{31} 3$ ) Life Orientation Test (LOT): 8 items measuring the personality trait optimism; ${ }^{32} 4$ ) General Self-Efficacy Scale (GSES), which measures the generalized belief that one has the skills to reach personal goals (10 items); ${ }^{33}$ and 5) Medical Outcomes Study Short-Form General Health Survey (SF-36), measuring 8 domains of health-related quality of life (pain interference, physical functioning, social functioning, role limitations functional, role limitations social, vitality, mental health, and general health) ${ }^{34}$ Completion of questionnaires took 15 to 20 minutes. Patients were requested to bring the completed questionnaires to the hospital on the day of admission.

One day before the operation, patients were visited on the ward by a research assistant who obtained informed consent and scored patients' preoperative pain on a 100-mm visual analogue scale (VAS). Patients also filled out one additional questionnaire on surgical anxiety. This 10-item questionnaire was adapted from Koivula et $\mathrm{al}^{35}$ who studied fear of coronary bypass surgery. For the present study, cardiac specific items and one item referring to death were removed.

\section{Postoperative Assessment}

Operations were independently categorized by 5 experienced anesthetists into 3 groups (minor, intermediate, and major) based on the anticipated level of postoperative pain and in accordance with Rawal's stepwise approach of acute pain treatment ${ }^{36}$ (Table 1). Subsequently, surgical procedures were categorized according to the anatomic region of the body involved (head/neck, upper extremities, thorax-noncardiac, abdominal high, abdominal low, abdominal high and low, lower extremities, back, multiple sites). Type of anesthesia was coded as general, locoregional, or general plus locoregional. Duration of the operation was dichotomized as $<3$ or $\geq 3$ hours. In addition, acute postoperative pain during the first 4 days after the operation was assessed. Pain intensity at rest, during deep breathing, and with coughing was scored 3 times a day on a $100-m m$ VAS.

Six months after surgery, participants were sent the long-term recovery questionnaire and the SF-36 by mail. We devised the long-term recovery questionnaire for the purpose of this study. It included the 1-item Global Surgical Recovery (GSR) index ("If 100\% recovery is back to the usual health you had before you got sick and had surgery, what percent of recovery you are at now?"). The GSR has been used previously and was found to correlate 0.72 with a more elaborate instrument of surgical recovery. ${ }^{37}$ Next were 4 questions to measure changes due to the operation in pain, mobility (walking, sitting, and lying down), self-care (washing and dressing), and activity level (sports and physical exertion). Each of these questions started by asking whether the patient experienced difficulties in the specified domain before the operation and whether he/she experienced difficulties at follow-up. When either of these questions was answered affirmatively the respondent was asked how the operation influenced the problem (much less, somewhat less, the same, somewhat more, much more). Presence of preoperative pain (no/yes) was also established by this questionnaire.

\section{Statistical Analyses}

The 4 outcome variables in the study were increased pain due to the operation (no/yes), increased functional limitations due to the operation (no/yes), poor global recovery (no/yes), and quality of life (continuous). Blockwise logistic regression analysis was used to identify the factors that were associated with the dichotomous outcome variables. In the 


\begin{tabular}{|c|c|c|}
\hline $\begin{array}{l}\text { Anticipated Postop. } \\
\text { Pain Level }\end{array}$ & Anatomic Region & Type of Operation \\
\hline \multirow[t]{6}{*}{ Minor } & Head and neck & $\begin{array}{l}\text { Thyroidectomy, stapedectomy, tympanoplasty, petrosal bone and } \\
\text { middle ear surgery, cochlear implantation, middle ear inspection, } \\
\text { middle ear reconstruction, auricle operation, nasal sinus operation, } \\
\text { endoscopy of pharynx, larynx, bronchus, craniotomy, eye surgery }\end{array}$ \\
\hline & Upper extremities & Peripheral vascular operations, wound toilet, sutures \\
\hline & Thorax: noncardiac & Vascular operations, wound toilet \\
\hline & Lower abdomen/pelvis & $\begin{array}{l}\text { Vaginal urologic procedures, cervix operation, abortion, } \\
\text { hysteroscopy, operations of male genital, endoscopic urologic } \\
\text { interventions like TUR, cystic biopsy, urethra, cystoscopy, plastic } \\
\text { skin operations }\end{array}$ \\
\hline & Lower extremities & Plastic skin operations, peripheral vascular operations, wound toilet \\
\hline & Back/spinal & Urologic neuromodulation, small plastic skin operations \\
\hline \multirow[t]{8}{*}{ Intermediate } & Head and neck & $\begin{array}{l}\text { Neck dissection, mouth and throat surgery, laryngectomy, pharynx } \\
\text { and larynx surgery, maxilla and mandibular surgery }\end{array}$ \\
\hline & Upper extremities & Orthopedic hand and arm surgery \\
\hline & Thorax: noncardiac & Plastic breast surgery \\
\hline & Upper abdomen & Fundoplication, duodenum surgery, cholecystectomy, nephrectomy \\
\hline & Lower abdomen/pelvis & $\begin{array}{l}\text { Surgery of vulva, ovary, adnexa, vaginal and abdominal uterus } \\
\text { extirpation, abdominal endometriosis, closure of anus prater, } \\
\text { colorectal surgery, anal surgery, abdominal vascular surgery, abd. } \\
\text { lipectomy, cystic resection, Ryntshak and radical prostatectomy }\end{array}$ \\
\hline & Lower extremities & $\begin{array}{l}\text { Plastic skin operations, orthopedic surgery foot } / \mathrm{knee} / \mathrm{leg} / \mathrm{hip} \text {, } \\
\text { amputation, peripheral vascular surgery }\end{array}$ \\
\hline & Back/spinal & $\begin{array}{l}\text { Plastic skin operations, spinal cord decompression with } \\
\text { hemilaminectomy, discectomy }\end{array}$ \\
\hline & $>1$ region & Plastic breast + abdominal surgery, arm/hand and hip (fractures) \\
\hline \multirow[t]{5}{*}{ Major } & Upper extremities & Shoulder surgery (endoprosthesis), clavicle surgery \\
\hline & Thorax: noncardiac & Lobectomy \\
\hline & Upper + lower abdomen & $\begin{array}{l}\text { Hepatectomy, pancreatectomy, combination of different bowel } \\
\text { surgery, aortic surgery, extensive gynecologic surgery, } \\
\text { combination of bowel and gynecologic surgery }\end{array}$ \\
\hline & Lower extremities & Total knee replacement \\
\hline & Back/spinal & Spondylodesis, untethering \\
\hline
\end{tabular}

first step, 2 variables describing the surgical procedure were entered: anticipated postoperative pain level and body region were the operation took place. In step 2, the demographic variables age, sex, and education were entered in the model. The contribution of the somatic variables preoperative pain, duration of the operation, anesthetic technique, acute postoperative pain, and ASA grade was examined in step 3. The psychologic variables were entered to the model in the final step. Psychologic variables were dichotomized by median split. Variables in step 1 and 2 were entered using a forced entrance procedure and variables in step 3 and 4 were entered with a forward procedure (likelihood ratio), using a criterion of $P<$ 0.10 for entering variables in the model. The significance of each step was tested using the $\chi^{2}$ statistic. The models' ability to discriminate between patients with a favorable and a nonfavorable outcome was estimated by the area under the receiver operant curve (AUC) for the successive steps.

Blockwise linear regression analysis was used to analyze the continuous variable quality of life (QOL). In step 1, the variables describing the surgical procedure were entered, together with preoperative level of QOL, to control for baseline differences. Step 2 entered the demographic vari- ables, step 3 the somatic variables, and step 4 the psychologic variables. For the linear regression analysis, the continuous quality of the psychologic variables was retained. Steps 3 and 4 again used a forward entry procedure with $P<0.10$ as the criterion for adding a variable. The significance of each step was tested using $\mathrm{F}$ change. The total amount of explained variance in QOL at follow-up is indicated by $R^{2}$. Analyses were performed with the Statistical Package for Social Sciences (SPSS), version 11.5.

\section{Ethical Considerations}

Before the operation patients were asked for consent to participate in a study including preoperative assessment and data collection of relevant variables until 4 days postoperatively. Separate informed consent was obtained for the follow-up part of the study 4 days after the operation.

\section{RESULTS}

\section{Dropout Analyses}

Compared with the initial sample of 1490 patients, study participants had somewhat higher education $(29.7 \%$ 
low education, $40.4 \%$ intermediate, and $29.9 \%$ high; in the initial sample these numbers were: 33.2, 37.9, and 28.9). Moreover, they less often had a major operation (17.8\% vs. $20 \%$ ), remained fewer days in hospital (6.0 days vs. 6.8 days), and were in better physical health before the operation (ASA grade I, $41.9 \%$ vs. $36.1 \%$ in initial sample).

\section{Data Reduction and Validity of Predictor Variables}

The surgical anxiety questionnaire was subjected to principal component analysis with oblimin rotation to identify its factor structure. Two components were found that explained $60 \%$ of total variance (eigenvalues, 4.8 and 1.2). The first component consisted of 6 items concerning the following fears (item loadings in parentheses): incomplete recovery (0.93), long duration of rehabilitation (0.83), nonsuccessful operation (0.78), adverse health effect (0.77), worries about family members (0.47), and stay in hospital (0.43). Together these items constituted a subscale that was termed "fear of long-term consequences of the operation" (Cronbach $\alpha=0.82$ ). The second component contained 4 items with fears concerning: anesthesia (0.90), the operation itself (0.84), unpleasant side effects $(0.70)$, and pain (0.66). This subscale was termed "fear of immediate consequences of the operation" (Cronbach $\alpha=0.83$ ). The intercorrelation between the subscales was 0.56 .

To check the validity of our retrospective measure of preoperative pain, we compared the preoperative pain intensity VAS and the SF-36 pain score of patients who did or did not report preoperative pain on the long-term follow-up questionnaire. The frequency distribution of the preoperative VAS and SF-36 pain scores showed clearly different patterns for the 2 groups in line with expectations. Patients reporting no preoperative pain retrospectively had an average preoperative pain score of 4 on the VAS and 84 on the SF-36 pain subscale, while patients with preoperative pain scored 22 on the VAS and 45 on the SF-36 pain subscale.

To quantify acute postoperative pain, we calculated an average pain intensity score for each of the 4 postoperative days on the basis of the VAS pain at rest. The 3 different pain scores (rest, coughing, breathing) were highly correlated (average Pearson $\mathrm{R}=0.87$; range, $0.75-0.98$ for the various time points) and only pain at rest had no missing values. For the logistic regression analyses, average pain intensity was transformed into a dichotomous variable according to VAS $<40$ or $\geq 40$.

\section{Increased Pain}

The outcome variable "increased pain due to the operation" was derived from the long-term recovery questionnaire and operationalized as "somewhat" or "much more" pain at follow-up than before the operation. More than $12 \%$ of patients $(\mathrm{n}=78 ; 12.5 \%)$ reported increased pain 6 months after the operation, ie, their preoperative pain had become worse $(n=37)$ or they had developed a new pain problem $(\mathrm{n}=41)$.

Blockwise multiple logistic regression analysis was used to test for significant predictors of increased pain. The step 1 variables anticipated postoperative pain level and body region yielded an AUC of $0.66\left(\chi^{2}=23.8, P=0.008\right)$. The inclusion of demographic variables in step 2 did not significantly improve the model $\left(\chi^{2}=1.2, P=0.88\right.$, AUC $\left.=0.67\right)$. The somatic variables entered in the third step did significantly contribute to the model $\left(\chi^{2}=29.4, P=0.001\right.$, AUC $\left.=0.74\right)$. In the final step fear of long-term consequences of the operation entered the model, increasing discriminative ability of the model to AUC = $0.75\left(\chi^{2}=5.1, P=0.024\right)$. Table 2 shows the results for the variables in the last 2 steps. In the final model, acute postoperative pain (4 days after the operation, OR, 3.21; 95\% CI, $1.6-6.3)$ and preoperative pain (OR, 0.32; 95\% CI, 0.17-0.60) were most strongly associated with increased pain at follow-up, followed by anticipated postoperative pain level (OR, 2.6; 95\% CI, 1.2-5.8 for intermediate vs. minor procedures) and duration of the operation $(\mathrm{OR}, 2.0 ; 95 \% \mathrm{CI}, 1.0-4.0)$ [acute postoperative pain scores on day 1 to 4 were used as independent variables in successive analyses. Each of these variables was significantly related to increased pain at follow-up, but pain on day 4 most strongly $(\mathrm{OR}=2.4$ for day $1,2.8$ for day $2,2.5$ for day 3 , and 3.2 for day 4 ). In all further analyses, pain intensity on day 4 was used]. High acute post operative pain, intermediate surgical procedures, and longer operations increased the risk of increased pain at follow-up, while pain before the operation decreased the risk. Fear of the long-term consequences of surgery further elevated the risk of increased pain at follow-up (OR, 1.9; 95\% CI, 1.1-3.3).

\section{Increased Functional Limitations}

Increased functional limitations due to the operation was scored from the long-term recovery questionnaire. Seventeen percent of patients $(n=105)$ reported that due to the operation they had "somewhat" or "much more" problems with mobility, self-care, or physical activity at follow-up than before the operation [validity of this retrospective report was checked by comparing the preoperative and follow-up SF-36 physical functioning score of patients with more, the same, and less perceived functional limitations. As expected, patients with more limitations at follow-up scored lower on the SF-36 physical functioning scale (49 at follow-up vs. 55 preoperatively), patients with same limitations had an identical score (79 at both assessments) and patients with less limitations scored higher on the SF-36 physical functioning scale (66 at follow-up vs. 49 preoperatively)].

Blockwise logistic regression analyses indicated that the surgical procedure variables entered in step 1 yielded a significant predictive model with an AUC of $0.68\left(\chi^{2}=39.9\right.$, $P=0.001)$. The step 2 demographic variables did not improve the model $\left(\chi^{2}=2.94, P=0.57\right.$, AUC $\left.=0.69\right)$, but the step 3 somatic variables did $\left(\chi^{2}=32.91, P=0.001\right.$, AUC $=0.75)$. None of the psychologic variables entered the model in step 4. The variables associated with increased functional limitations at follow-up were anticipated postoperative pain level (OR, 2.7; 95\% CI, 1.3-5.8 for intermediate vs. minor procedures; OR, 3.3; 95\% CI, 1.2-9.2 for major vs. minor procedures), ASA status (OR, 2.4; 95\% CI, 1.2-4.9 for ASA grade III vs. grade I), duration of the operation (OR, 4.2; 95\% CI, 2.3-7.7), and pain 4 days after the operation (OR, $1.9 ; 95 \% \mathrm{CI}, 1.0-3.4)$. Results for step 3 and 4 predictor variables can be found in Table 2 . 
TABLE 2. The Association of Step 3 and 4 Predictor Variables With Outcome Variables Increased Pain at 6-Month Follow-up, Increased Functional Limitations at 6-Month Follow-up and Poor Global Recovery

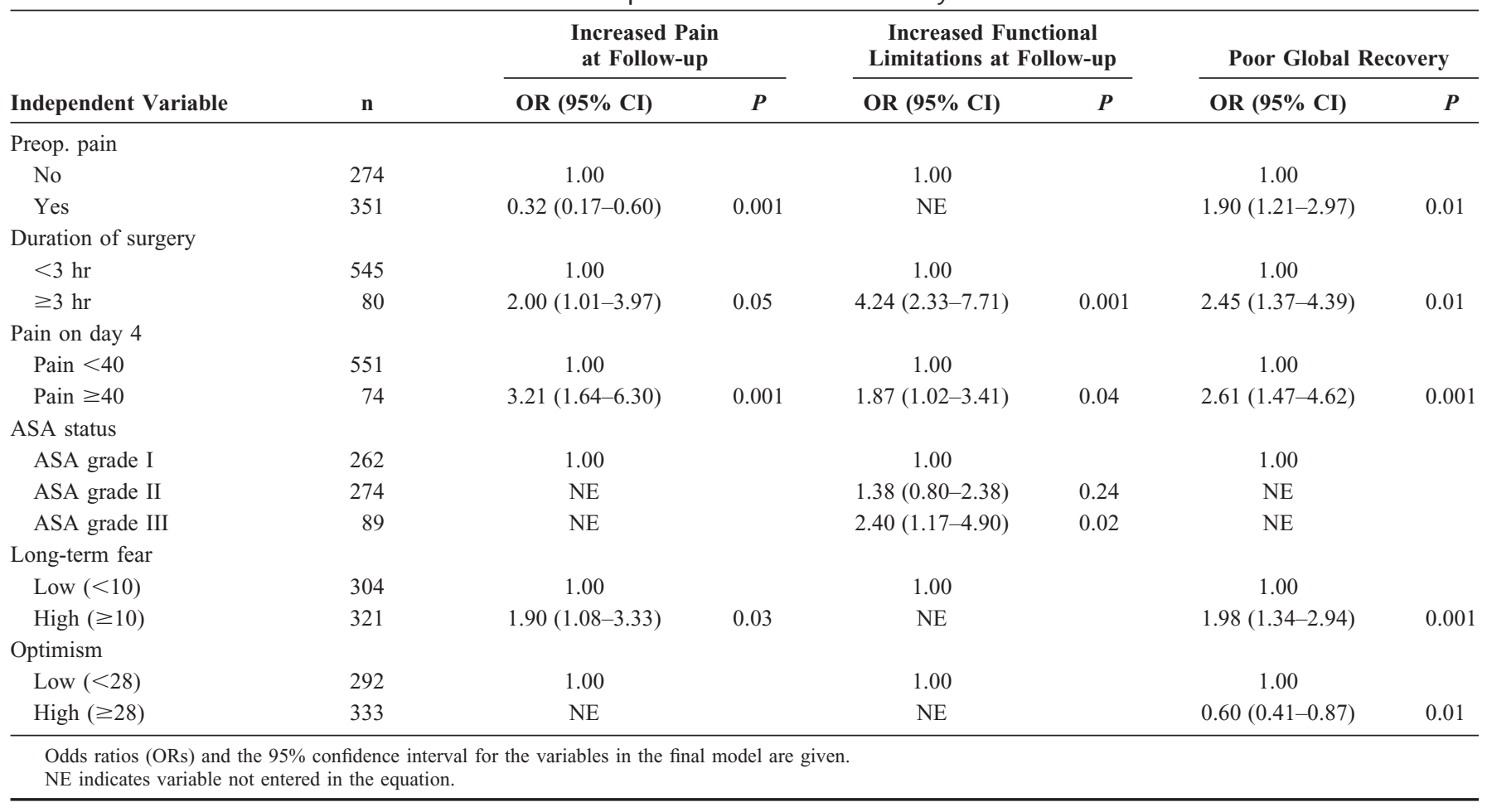

\section{Poor Global Recovery}

On average, patients reported to have recovered $78 \%$ (SD, 25; range, $0-100$ ) on the global surgical recovery index. Poor global recovery was defined as a score of $80 \%$ or less on this index. According to this criterion, 215 patients (34.4\%) reported poor recovery at 6 months postoperation.

The logistic regression analysis demonstrated that poor global recovery was significantly predicted by the variables coding the surgical procedure $\left(\chi^{2}=63.5, P=0.001\right.$, AUC $=$ 0.68). Demographic variables improved the model $\left(\chi^{2}=\right.$ $12.8, P=0.01, \mathrm{AUC}=0.71)$. The somatic variables in step 3 increased the AUC to $0.76\left(\chi^{2}=41.9, P=0.001\right)$ and the psychologic variables in step 4 to $0.77\left(\chi^{2}=20.0, P=\right.$ $0.001)$. The variables coding surgical procedure and the somatic variables in the full regression model associated with poor recovery were body region (upper extremities/shoulder operations associated with poor outcome, OR, 2.9; 95\% CI, 1.2-6.8; lower abdominal operations associated with good outcome, OR, 0.42; 95\% CI, 0.25-0.73), duration of the operation (OR, 2.4; 95\% CI, 1.4-4.4), pain 4 days after the operation (OR, 2.6; 95\% CI, 1.5-4.6), and preoperative pain (OR, 1.9; 95\% CI, 1.2-3.0). Female sex was associated with a somewhat better global recovery (OR, 0.67; 95\% CI, 0.44-0.98). Psychologic variables further contributed to the model with long-term fear of the consequences of surgery being associated with poor global recovery $(\mathrm{OR}, 2.0 ; 95 \% \mathrm{CI}$, 1.3-2.9) and optimism with good recovery (OR, 0.60; 95\% CI, 0.41-0.87). See Table 2 for an overview of the step 3 and 4 variables.

\section{Quality of Life}

To reduce the number of outcome variables related to quality of life, principal component analysis was conducted on the 8 subscales of the SF-36. All subscales loaded on a single factor (eigenvalue 5.0), explaining $62.4 \%$ of variance (individual factor loadings ranging between 0.73 and 0.88 ). The aggregated QOL score had high internal consistency (Cronbach $\alpha=0.89$ ) and was used in further analyses.

On average, patients showed improved quality of life at 6 months follow-up, with an aggregated QOL score of 62 (SD, 22.2) preoperation and 67.9 (SD, 21.7) at follow-up. Linear regression analysis indicated that most of the variance in QOL at follow-up (37\%) was explained by the variables in step 1 and especially preoperative QOL. The demographic variables in step 2 significantly contribute to the model, explaining an additional $2 \%$ variance, while the somatic variables in step 3 explained $5 \%$ of unique variance. Lower education, higher pain intensity at day 4 postoperatively, longer duration of the operation and ASA grade III were associated with decreased QOL, and lower abdominal operations were associated with increased QOL at follow-up. Step 4 added $1 \%$ of unique explained variance. Higher fear of the long-term consequences of the operation was associated with lower QOL and higher optimism with higher QOL. The final model could explain $45 \%$ of the variance in QOL at follow-up. Results are shown in Table 3.

\section{DISCUSSION}

A total of 625 patients undergoing various types of surgical intervention were followed for 6 months to establish 
TABLE 3. Results of the Linear Regression Analysis for the Aggregated SF-36 Quality of Life Score at 6-Month Follow-up

\begin{tabular}{|c|c|c|c|}
\hline & $R^{2}$ & F Change & $\boldsymbol{P}$ \\
\hline Step 1 & 0.368 & 31.7 & 0.001 \\
\hline Step 2 & 0.384 & 3.81 & 0.05 \\
\hline Step 3 & 0.434 & 13.1 & 0.001 \\
\hline \multirow[t]{2}{*}{ Step 4} & 0.448 & 7.31 & 0.001 \\
\hline & Standard B & $\boldsymbol{P}$ & \\
\hline Preoperative QOL & 0.456 & 0.001 & \\
\hline \multicolumn{4}{|c|}{ Anticipated postoperative pain level } \\
\hline Intermediate & 0.063 & 0.15 & \\
\hline Major & 0.050 & 0.36 & \\
\hline \multicolumn{4}{|l|}{ Body region } \\
\hline Head/neck & 0.243 & 0.09 & \\
\hline Upper extremities & 0.090 & 0.20 & \\
\hline Thorax: noncardiac & 0.067 & 0.32 & \\
\hline Abdominal high & 0.082 & 0.22 & \\
\hline Abdominal low & 0.283 & 0.04 & \\
\hline Abdominal high and low & 0.180 & 0.07 & \\
\hline Lower extremities & 0.229 & 0.08 & \\
\hline Back & 0.134 & 0.17 & \\
\hline Age & -0.014 & 0.69 & \\
\hline Sex & -0.005 & 0.88 & \\
\hline \multicolumn{4}{|l|}{ Education* } \\
\hline Low & -0.092 & 0.02 & \\
\hline Middle & -0.077 & 0.04 & \\
\hline Duration of surgery & -0.094 & 0.01 & \\
\hline Pain intensity day 4 & -0.169 & 0.001 & \\
\hline \multicolumn{4}{|l|}{ ASA status ${ }^{\dagger}$} \\
\hline ASA grade II & -0.062 & 0.09 & \\
\hline ASA grade III & -0.127 & 0.001 & \\
\hline Long-term fear & -0.080 & 0.02 & \\
\hline Optimism & 0.090 & 0.01 & \\
\hline
\end{tabular}

Significance and $R^{2}$ for each of the steps in the model are shown together with the standardized betas for all variables in the final model.

* Reference category: high education.

${ }^{\dagger}$ Reference category: ASA grade I.

predictors of adverse outcome. Several somatic and psychologic predictors of increased pain, functional limitations, global recovery, and quality of life at follow-up were identified by means of blockwise regression analysis in which clusters of variables were added to the prediction model.

The first cluster consisted of 2 variables coding the surgical procedure: anticipated (acute) postoperative pain level and body region of the operation. Operations classified as "intermediate" in terms of anticipated painfulness were significantly more often associated with increased pain and increased functional limitations at 6 months follow-up compared with minor operations. "Major" operations were associated with increased functional limitations but not with increased pain at follow-up. It should be noted that according to the prevailing protocol of postoperative pain management the classification into minor, intermediate, and major has implications for acute postoperative pain treatment. Procedures with higher anticipated postoperative pain levels were followed by stronger analgesic interventions, ie, procedures classified as major were treated with continuous epidural infusion of bupivacaine $0.125 \%$ with sufentanil $1 \mu \mathrm{g} / \mathrm{mL}$ or with patient-controlled intravenous administration of piritramide. Therefore, actual postoperative pain level after major operations was in many instances not higher than after procedures classified as minor or intermediate.

Anatomic region of the body involved was not a major predictor of outcome. Neither increased pain nor increased functional recovery was associated with operations in a specific body region. Global recovery and quality of life at follow-up did, however, show an association with body region: patients with upper extremity/shoulder operations had an elevated risk of poor global recovery and patients with lower abdominal operations had a lower risk of poor global recovery and reported increased levels of QOL at follow-up. It should be admitted that our classification into body regions was fairly crude, clustering sometimes heterogeneous procedures into the same category, but group sizes did not allow further differentiation.

The contribution of demographic variables was tested in the second step of the regression models. Younger age and female gender have been associated with an increased risk of chronic postoperative pain in previous studies, but these variables appeared unrelated to most of the outcome variables in the present study. Female gender even appeared to be protective against poor global recovery.

Various of the somatic variables that were added to the model in the third step showed a relatively strong association with outcome. Operations with a duration longer than 3 hours had a significantly higher chance of increased pain, increased functional limitations, and poor global recovery 6 months after surgery. Duration of the operation also influenced the change in quality of life from preoperation to 6-month follow-up. Another prominent predictor of long-term unfavorable outcome was a high level of acute postoperative pain. Patients with a VAS $\geq 40$ on postoperative day 4 had a higher chance of experiencing increased pain, increased functional limitations, and poor global recovery 6 months after the operation. High acute postoperative pain also negatively affected quality of life 6 months after surgery. These results coincide with previous findings demonstrating that more intense acute postoperative pain may be a risk factor for the development of chronic pain $2,3,9,11,14$ and delays functional recovery 6 months later. ${ }^{7}$ The strong associations found between both the duration of the operation and acute postoperative pain and unfavorable outcome may point to the role of central sensitization. Longer operations are associated with more enduring nociceptive barrage during surgery while high acute postoperative pain levels lead to intense and enduring nociceptive input in the postoperative period. Both may increase the chance of central sensitization and subsequently persistent pain. ${ }^{13,38}$

An inconsistent finding arose for the influence of preoperative pain. Having pain before the operation was associated with a lower chance of increased pain at follow-up, but it increased the chance of poor global recovery. Previous studies have found preoperative pain to increase the chance of chronic pain. $2,3,10$ ASA status was significantly associated 
with increased functional limitations and the change in QOL 6 months after the operation. Patients with ASA grade III experienced more functional limitations and showed less improvement in QOL at follow-up compared with patients with ASA grade I. Thus, being in a poor physical condition before the operation may constitute a risk factor for adverse functional outcome.

In the last cluster, the contribution of several psychologic variables was tested. For all outcome variables except increased functional limitations, psychologic variables added to the predictive power of the model. In line with studies on acute postoperative pain and recovery, ${ }^{17-20}$ fear of surgery proved to be the most consistent psychologic predictor of unfavorable outcome. Patients who were fearful of the longterm consequences of the operation had an increased chance of more pain and poor recovery at follow-up. In addition, fear had a negative influence on the improvement of QOL 6 months after the operation. Pain catastrophizing was recently identified as an important predictor of acute postoperative pain, ${ }^{21,22}$ but it did not turn up as a risk factor for long-term increases in pain or functional limitations in the present study. Probably the surgical fear questionnaire more closely taps the various concerns of patients undergoing an operation than the pain catastrophizing scale, which focusses uniquely on the pain experience.

Various studies have reported that optimism promotes recovery after surgical intervention. ${ }^{25} \mathrm{We}$ found that an optimistic attitude did not protect against increased pain or increased limitations in physical functioning 6 months after surgery, but that it did influence patients' overall estimates of their recovery and QOL at follow-up. Optimistic people may be more inclined to rate their recovery as satisfactory independent of the level of pain and limitations they experience. Moreover, they may be more resistant to the negative influence of pain and limitations on their QOL.

A limitation of the present study concerns the exclusion of patients who experienced complications during surgery and patients who were transferred to the intensive care unit because they needed extended ventilatory support. Because of practical constraints, these patients could not be approached for immediate postoperative assessment. In addition, patients declining participation were more often in bad physical condition preoperatively (ie, ASA grade III). This may limit the generalizability of the findings since there may have been a selective dropout of patients most at risk for long-term unfavorable outcome. Prevalence of unfavorable outcome may thus be higher than we report in the present study. However, despite this potential underestimation, predictors of unfavorable outcome could be identified.

\section{CONCLUSION}

We identified several somatic and psychologic predictors of long-term unfavorable outcome. The most important somatic predictors were operations with a duration longer than 3 hours and high acute postoperative pain. Although we should be cautious with a causal interpretation of the results, the implication of this could be that adequate treatment of acute postoperative pain may reduce the risk of long-term adverse outcome. Furthermore, patients who are in a bad physical condition preoperatively (ASA grade III) may require extra attention postoperatively as they are at risk for further deterioration of their condition. The most important psychologic predictor appeared to be fear of surgery. Identification of patients with high levels of fear and subsequently reducing these fears may promote recovery and reduce the risk of adverse outcome. Interventions to better prepare people for surgery have been found to be able to reduce patients' fear, reduce postoperative pain, and aid recovery. ${ }^{39,40}$ Clearly, more research into somatic and psychologic interventions to prevent long-term unfavorable outcomes of surgery is warranted.

\section{REFERENCES}

1. Macrae WA. Chronic pain after surgery. Br J Anaesth. 2001;87:88-98.

2. Perkins FM, Kehlet H. Chronic pain as an outcome of surgery: a review of predictive factors. Anesthesiology. 2000;93:1123-1133.

3. Kehlet H, Jensen TS, Woolf CJ. Persistent postsurgical pain: risk factors and prevention. Lancet. 2006;367:1618-1625.

4. Bruce J, Drury N, Poobalan AS, et al. The prevalence of chronic chest and leg pain following cardiac surgery: a historical cohort study. Pain. 2003; 104:265-273.

5. Eisenberg E, Pultorak Y, Pud D, et al. Prevalence and characteristics of post coronary artery bypass graft surgery pain (PCP). Pain. 2001;92: $11-17$.

6. Smith WC, Bourne D, Squair J, et al. A retrospective cohort study of post mastectomy pain syndrome. Pain. 1999;83:91-95.

7. Wallace MS, Wallace AM, Lee J, et al. Pain after breast surgery: a survey of 282 women. Pain. 1996;66:195-205.

8. Kumar S, Wilson RG, Nixon SJ, et al. Chronic pain after laparoscopic and open mesh repair of groin hernia. Br J Surg. 2002;89:1476-1479.

9. Callesen T, Bech K, Kehlet H. Prospective study of chronic pain after groin hernia repair. Br J Surg. 1999;86:1528-1531.

10. Poobalan AS, Bruce J, King PM, et al. Chronic pain and quality of life following open inguinal hernia repair. Br J Surg. 2001;88:1122-1126.

11. Poobalan AS, Bruce J, Smith WC, et al. A review of chronic pain after inguinal herniorrhaphy. Clin J Pain. 2003;19:48-54.

12. Cunningham J, Temple WJ, Mitchell P, et al. Cooperative hernia study: pain in the postrepair patient. Ann Surg. 1996;224:598-602.

13. Coderre TJ, Katz J, Vaccarino AL, et al. Contribution of central neuroplasticity to pathological pain: review of clinical and experimental evidence. Pain. 1993;52:259-285.

14. Katz J, Jackson M, Kavanagh BP, et al. Acute pain after thoracic surgery predicts long-term post-thoracotomy pain. Clin J Pain. 1996;12:50-55.

15. Hannan EL, Magaziner J, Wang JJ, et al. Mortality and locomotion 6 months after hospitalization for hip fracture: risk factors and riskadjusted hospital outcomes. JAMA. 2001;285:2736-2742.

16. Orbell S, Johnston M, Rowley D, et al. Self-efficacy and goal importance in the prediction of physical disability in people following hospitalization: a prospective study. Br J Health Psychol. 2001;6:25-40.

17. Taenzer P, Melzack R, Jeans ME. Influence of psychological factors on postoperative pain, mood and analgesic requirements. Pain. 1986;24: 331-342.

18. Munafo MR, Stevenson J. Anxiety and surgical recovery: reinterpreting the literature. J Psychosom Res. 2001;51:589-596.

19. Caumo W, Schmidt AP, Schneider CN, et al. Preoperative predictors of moderate to intense acute postoperative pain in patients undergoing abdominal surgery. Acta Anaesthesiol Scand. 2002;46:1265-1271.

20. Kalkman CJ, Visser K, Moen J, et al. Preoperative prediction of severe postoperative pain. Pain. 2003;105:415-423.

21. Pavlin DJ, Sullivan MJ, Freund PR, et al. Catastrophizing: a risk factor for postsurgical pain. Clin J Pain. 2005;21:83-90.

22. Granot M, Ferber SG. The roles of catastrophizing and anxiety in the prediction of postoperative pain intensity: a prospective study. Clin J Pain. 2005;21:439-445. 
23. Kendell K, Saxby B, Farrow M, et al. Psychological factors associated with short-term recovery from total knee replacement. $\mathrm{Br} J$ Health Psychol. 2001;6:41-52.

24. Scheier MF, Matthews KA, Owens JF, et al. Optimism and rehospitalization after coronary artery bypass graft surgery. Arch Intern Med. 1999; 159:829-835.

25. Scheier MF, Matthews KA, Owens JF, et al. Dispositional optimism and recovery from coronary artery bypass surgery: the beneficial effects on physical and psychological well-being. J Pers Soc Psychol. 1989;57: 1024-1040.

26. Waldrop D, Lightsey O, Ethington C. Self-efficacy, optimism, health competence, and recovery from orthopedic surgery. J Counsel Psychol. 2001;48:233-238.

27. Bowley DM, Butler M, Shaw S, et al. Dispositional pessimism predicts delayed return to normal activities after inguinal hernia operation. Surgery. 2003;133:141-146.

28. King KB, Rowe MA, Kimble LP, et al. Optimism, coping and long-term recovery from coronary artery surgery in women. Res Nurs Health. 1998;21:15-26.

29. Orbell S, Johnston M, Rowley D, et al. Cognitive representations of illness and functional and affective adjustment following surgery for osteoarthritis. Soc Sci Med. 1998;47:93-102.

30. Sullivan MJL, Bishop SR, Pivik J. The Pain Catastrophizing Scale: development and validation. Psychol Assessment. 1995;7:524-532.

31. Carver CS, White TL. Behavioral inhibition, behavioral activation, and affective responses to impending reward and punishment: the BIS/BAS Scales. J Pers Soc Psychol. 1994;67:319-333.

32. Scheier MF, Carver CS, Bridges MW. Distinguishing optimism from neuroticism (and trait anxiety, self-mastery, and self-esteem): a reevaluation of the Life Orientation Test. J Pers Soc Psychol. 1994;67:10631078.

33. Jerusalem M, Schwarzer R. Self-efficacy as a resource factor in stress appraisal processes. In: Schwarzer R, ed. Self-Efficacy: Thought Control of Action. Washington, DC: Hemisphere, 1992:195-213.

34. Rand Health Science Program. Rand 36-item Health Survey Manual. Santa Monica, CA: Rand, 1992.

35. Koivula M, Tarkka MT, Tarkka M, et al. Fear and anxiety in patients at different time-points in the coronary artery bypass process. Int J Nurs Stud. 2002;39:811-822.

36. Rawal N. Organization, function, and implementation of acute pain service. Anesthesiol Clin North Am. 2005;23:211-255.

37. Kleinbeck SV. Self-reported at-home postoperative recovery. Res Nurs Health. 2000;23:461-472.

38. Stubhaug A. Can opioids prevent post-operative chronic pain? Eur J Pain. 2005;9:153-156.

39. Gammon J, Mulholland CW. Effect of preparatory information prior to elective total hip replacement on psychological coping outcomes. $J$ Adv Nurs. 1996;24:303-308.

40. Lin LY, Wang RH. Abdominal surgery, pain and anxiety: preoperative nursing intervention. J Adv Nurs. 2005;51:252-260. 